\title{
AWJM Performance Measurement of Sandwich Composites
}

\author{
Avinash Shinde, I. Siva
}

\begin{abstract}
Sandwich composites, wherein the skin and core fulfills the requirement of different properties, like in foam sandwich structure, foam is providing damping and skin provides rigidity to the structure. In this work a sandwich panels with foam core and glass/polyester skin is fabricated by vacuum infusion technique. Abrasive water-jet drilling of these materials is performed to study the effect of standoff distance (SOD), Water Jet Pressure (JP) and Traverse Rate (TR) on kerf taper and surface roughness and Material Removal Rate (MRR). The experiment is designed using Taguchi's L9 orthogonal array. The ANOVA is done to study the influence of input parameters on output. It is found that SOD is the most influencing parameter on the kerf taper and surface roughness..
\end{abstract}

Keywords : AWJM, Sandwich, Composite, Machining, glass fiber, ANOVA

\section{INTRODUCTION}

There are many applications where structures need to be thick but light weight as well. This can be effectively done by using the sandwich composites [1] [2]. The core gives required thickness and skin provides the strength. For maintain precise tolerance and finish composites are required to be machined also it is found that the process of machining affect the mechanical property of composites [3]. So it becomes imperative to study the machining performance of the sandwich composites. Abrasive water jet machining (AWJM) is the popular un conventional machining process in industry because of advantages like, it does not produce chatter, thermal distortion. The problems in AWJM machining are kerf taper and delamination which are decided by the AWJM process parameters viz. SOD, JP, TR, etc [4]. The majority of studies are focused on evaluating the influence these parameters for laminated composites using ANOVA [5-9].

A wide variety of literature is available on AWJM performance of laminated composites but literature on AWJM of sandwich composite is not available. It is important and interesting to understand the response of the sandwich structures to the un conventional machining process. This paper gives the detailed analysis of AWJM process parameter influence using the ANOVA

Revised Manuscript Received on December 30, 2019.

* Correspondence Author

Avinash Shinde, Department of Mechanical Engineering MKSSS's Cummins College of Engineering for Women Pune 411052, Maharashtra, India.Email: amico@ufrgs.br

I. Siva* , Department of Mechanical Engineering, Kalasalingam Academy of Research and Education, Krishnankoil-626 126, India, Email: isiva@klu.com

\section{MATERIALS AND METHODS}

\section{A. Material and manufacturing details}

Table 1 gives the details of material used for manufacturing of glass/PVC/glass sandwich. The specimen is manufactured by vacuum infusion method. Uniform distribution of resin is ensured by creating a vacuum and collecting excess resin at the outlet. This also ensures uniform thickness of skin. Figure 1 shows the manufactured specimen with skin and core.

. Table 1. Materials details

\begin{tabular}{|c|c|c|}
\hline & Layers & Material \\
\hline \multirow[b]{2}{*}{ Skin } & Reinforcement & Glass \\
\hline & Matrix & $\begin{array}{c}\text { Polyester } \\
\text { (ARAZYN® 13.0) }\end{array}$ \\
\hline \multicolumn{2}{|r|}{ Core } & $\operatorname{PVC}(80 \mathrm{~g} / \mathrm{cc})$ \\
\hline \multicolumn{2}{|c|}{ Accelerator } & $\begin{array}{c}\text { acetyl acetone peroxide } \\
\text { (AAP) }\end{array}$ \\
\hline
\end{tabular}

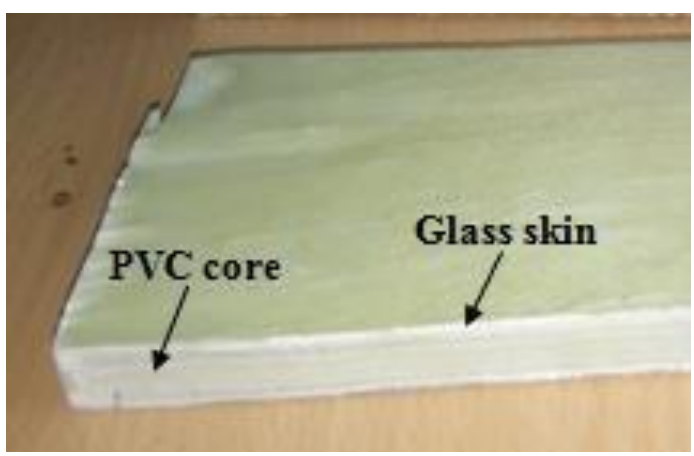

Fig. 1. Glass/PVC/Glass sandwich composite specimen

\section{B. Experimental Design}

Taguchi's experimental design is used for designing the experiment. Table 1 gives the AWJM process parameters and different levels. A through slot of $15 \mathrm{~mm}$ length is created in the specimen on CNC AWJ machine taking fixed nozzle diameter of $0.7 \mathrm{~mm}$ and garnet abrasives with 80 mesh size are used. 
AWJM Performance Measurement of Sandwich Composites

Table 2. Selected levels of different parameters

Levels

Process Parameters

\begin{tabular}{lccc} 
& -1 & 0 & 1 \\
\hline Stand off Distance (SOD) (mm) & 1 & 2 & 3 \\
Jet Presure (P) (Bar) & 168 & 216 & 264 \\
Traverse Rate (TR) (mm/min) & 10 & 20 & 30
\end{tabular}

\section{Measurement of kerf taper, surface roughness and MRR}

Top and bottom kerf width is measured by using microscope with 5 Megapixel camera. Average kerf width is calculated by taking three reading on top and bottom surface. The kerf taper is calculated by using equation 1 .

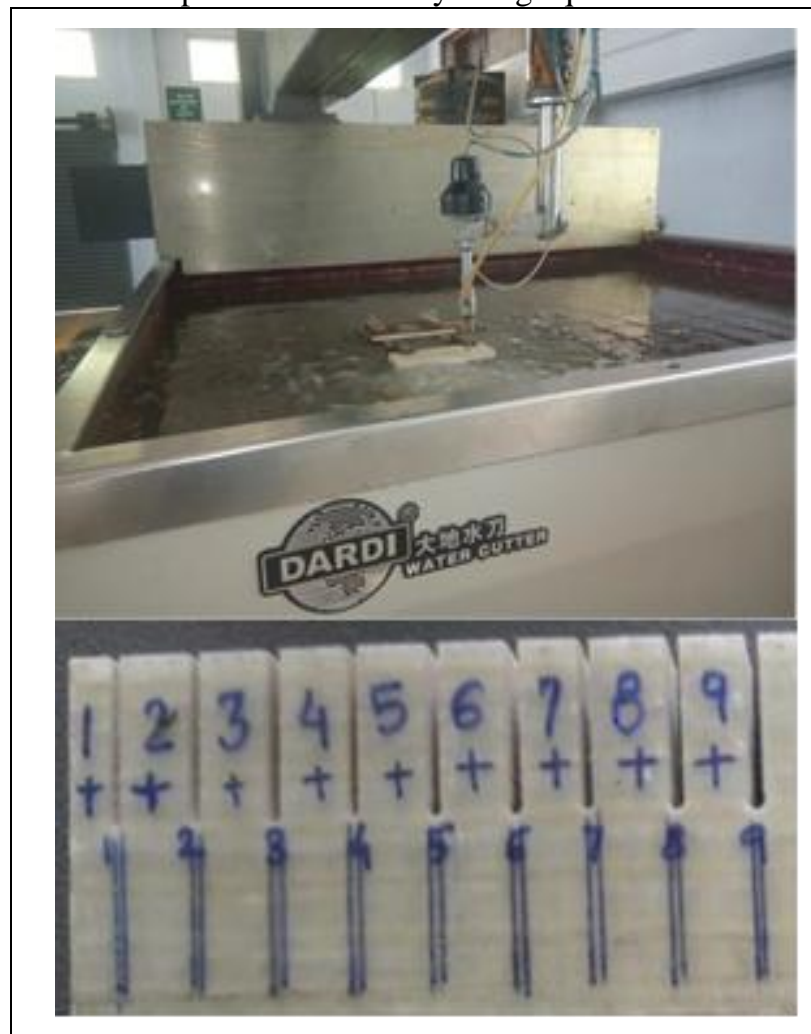

. Fig. 2. AWJM machining set up (a), machined Glass/PVC/Glass sandwich composite (b)

$$
\text { Kerf Taper Angle }(\theta)=\tan ^{-1}\left(\frac{W_{1}-W_{2}}{2 \times t}\right)
$$

Where, W1 and W2are top and bottom width of kerf and $\mathrm{t}=$ Thickness of specimen

$$
M R R=\text { depth of cut } \times\left(\frac{W_{T+} W_{B}}{2}\right) \times T R
$$

MRR calculated from the traverse rate by using equation 2. Surface roughness is measured using Mitutoyo SJ - 410 surface roughness tester. Damage and stray marks on surface are observed by doing scanning electron microscopy (SEM).

Optimum levels and influence of process parameter is evaluated using ANOVA. For predicting the responses with a given set of input parameters, linear regression model is developed.

\section{RESULTS AND DISCUSSION}

The ANOVA is done for finding the influencing parameter. The following sections give the details of the ANOVA study.

\section{A. Analysis of The Influence of AWJM process parameters}

The results of ANOVA for kerf taper shows the model is significant and SOD is the deciding parameters for kerf taper. The ratio of maximum to minimum kerf taper angle is 4.5. Equation 3 gives the linear regression equation for predicting kerf taper angle. The Predicted $\mathrm{R}^{2}$ of 0.6685 is in reasonable agreement with the Adjusted $\mathrm{R}^{2}$ of 0.8035 ; i.e. the difference is less than 0.2

Kerf Taper angle $=0.6667-0.000389 \mathrm{JP}+0.1060 \mathrm{SOD}$ $0.00121 \mathrm{TR}$

The optimized process parameters for getting minimum kerf taper are depicted in figure 3 (a). JP decides the cutting abilityof the AWJM and as pressure increases the material can be easily cut and there are less chances of kerf taper. As can be seen, kerf taper is found to decrease as JP decreases and SOD increases. This observation is not typical in AWJM. Increase in pressure may lead to removing extra material from the soft PVC core leading to more kerf taper. For higher SOD the jet may diverge and the outer ring of the jet with less energy may not be able remove excess material causing less kerf taper.

From the contour plots for the kerf taper (Figure 3 (a-c)) the influence of different process parameters can be seen. It can be observed that the SOD greater than $2.5 \mathrm{~mm}$ and TR greater than $26 \mathrm{~mm} / \mathrm{min}$ gives minimum kerf taper for the studied pressure range. The TR between 12 to $25 \mathrm{~mm} / \mathrm{min}$ should be avoided for better kerf quality.

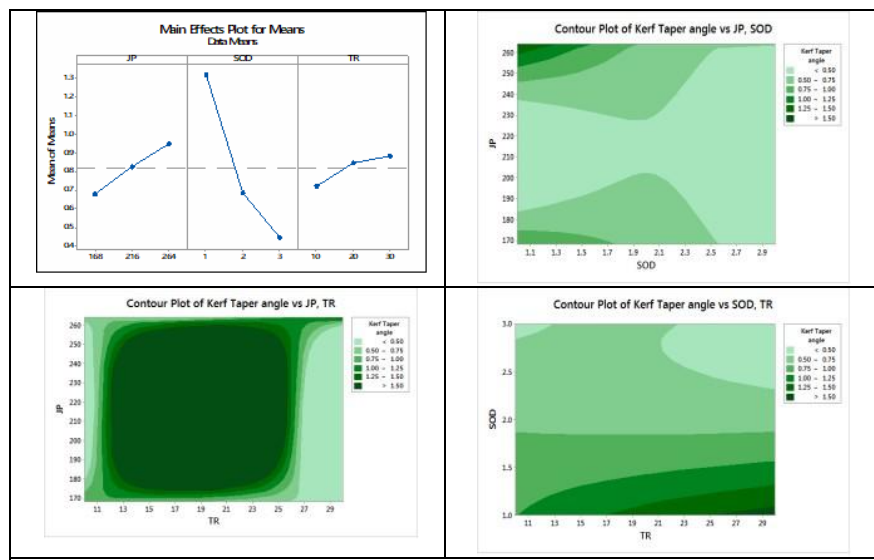

Fig. 3. (a) Main effects plot for means, Contour plots of effect of (b) JP and SOD (c) JP and TR, (d) TR and SOD on roughness.

From ANOVA analysis it is seen that the model is significant and JP is the most influencing parameter as p value is less than 0.05 . The linear regression model is given in equation 4 Roughness $=17.30-0.03343 \mathrm{JP}+0.659 \mathrm{SOD}+0.0067$

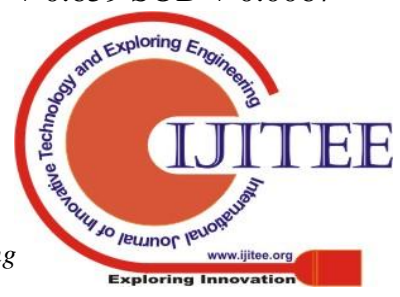


TR

The main effect plot depicts the influence of JP on the surface roughness. The optimized values of JP, SOD and TR for obtaining good surface finish are $268 \mathrm{MPa}, 1 \mathrm{~mm}$ and 10 $\mathrm{mm} / \mathrm{min}$ respectively. Higher JP eases the material removal and gives better surface finish. Second parameter which influences the surface roughness is SOD. The jet divergence at lower SOD is less and hence the kinetic energy of jet produces higher impact on the surface which eases material removal and surface finish is improved. The range of 15-25 $\mathrm{mm} / \mathrm{min}$ should be avoided to get good surface finish

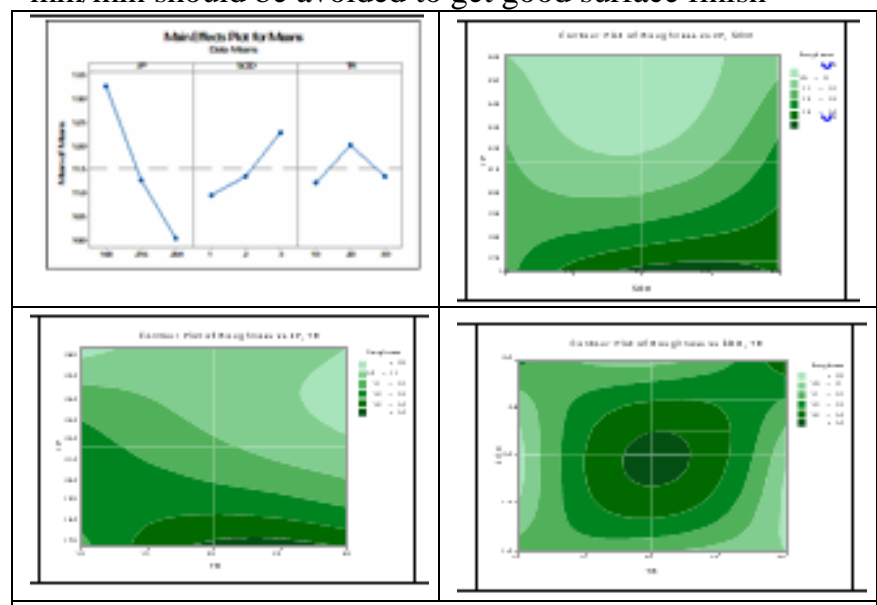

Fig. 4. (a) Main effects plot for means, Contour plots of effect of (b) JP and SOD (c) JP and TR, (d) TR and SOD on surface roughness

Higher TR and JP are favorable parameters for increasing the MRR and same can be observed in figure 5 (a). The ANOVA analysis shows the model is significant and the R2. Predicted (0.9653) is closely related to R2 adjusted (0.9931). The linear regression analysis is done for developing the prediction model given in equation5

$\mathrm{MRR}=-74.6+0.3895 \mathrm{JP}-6.67 \mathrm{SOD}+13.458 \mathrm{TR}--(5)$

Form figure 5 (c-d) it can be seen that the MRR is independent of JP and SOD for the traverse rate greater than $20 \mathrm{~mm} / \mathrm{min}$

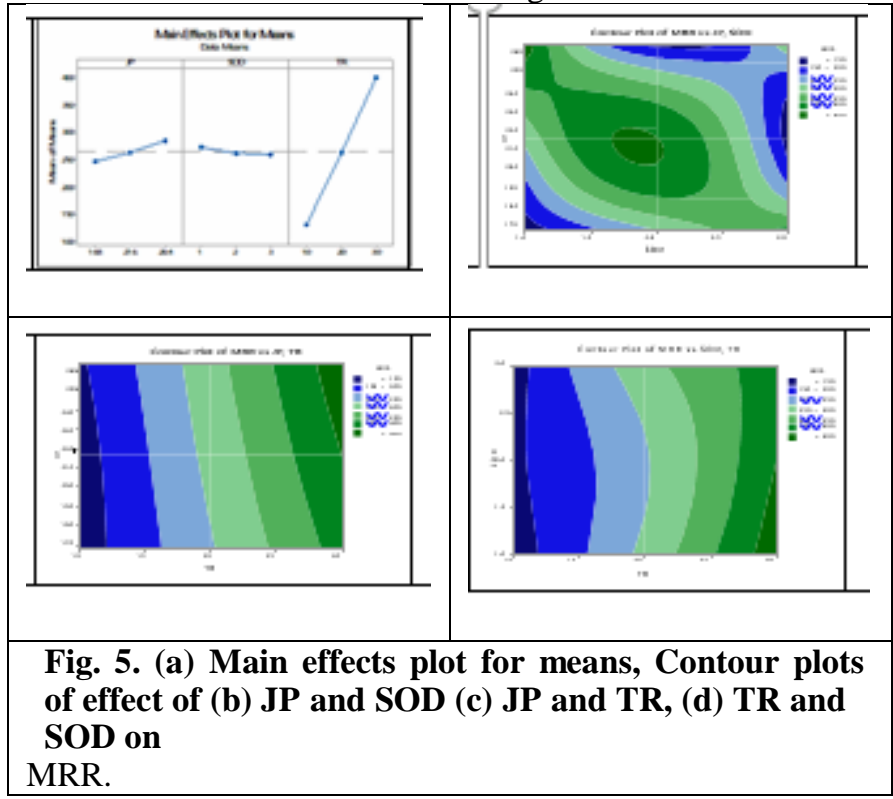

As can be seen from figure $5(a-b)$ the PVC core experiences more damage because of its porous nature. The surface roughness is also high in this region due to damaged surface. In figure 5 (c) $\neg$ the skin-core interfacial damage can visible.
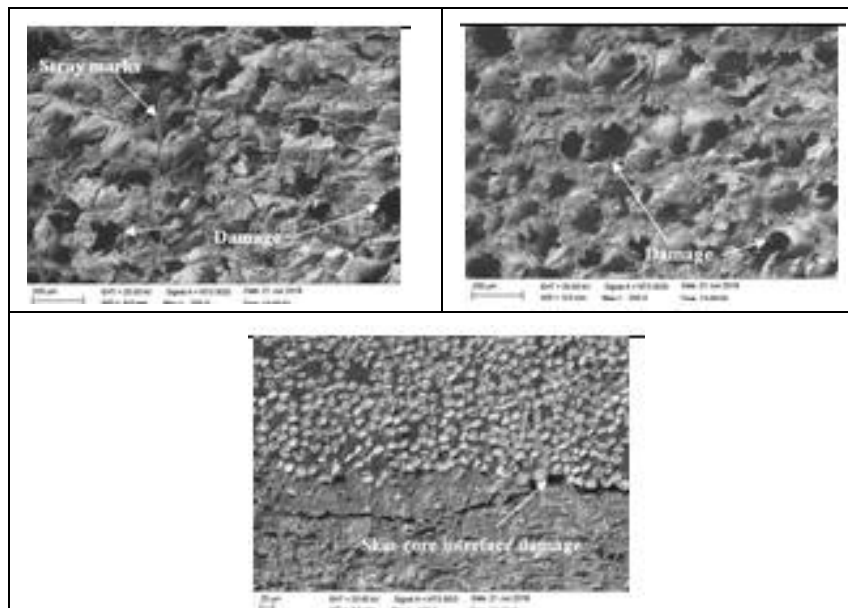

6. (a-b) Stray marks and damages on core (c) skin-core interfacial damage

\section{B. Experimental confirmation of model}

The final step is to validate the regression model with the experimental results. The developed regression models (equation 3-5) resulted in only 6-10\% error in different responses and hence it is believed to be validated. Table 6 gives the predicted and experimental results of the confirmation test.

\section{CONCLUSION}

The optimization study helps to understand the influence of different process parameters. The key observations are summarized below.

- High level of jet pressure is useful for obtaining better responses for kerf taper, surface roughness and MRR.

- $\quad$ SOD should be high for better kerf taper whereas it should be low for better surface finish and improved MRR.

- TR affects more on the MRR and it should be high to increase material removal rate.

\section{REFERENCES}

[1] A. Cherniaev and I. Telichev, "Weight-Efficiency of Conventional Shielding Systems in Protecting Unmanned Spacecraft from Orbital Debris,"J. Spacecr. Rockets, no. September 2016, pp. 1-15, 2016.

[2] V. Birman and G. A. Kardomateas, "Review of current trends in research and applications of sandwich structures," Compos. Part B Eng., vol. 142, no. January, pp. 221-240, 2018.

[3] M. Haddad, R. Zitoune, F. Eyma, and B. Castanié, "Influence of Machining Process and Machining Induced Surface Roughness on Mechanical Properties of Continuous Fiber Composites," Exp. Mech. vol. 55 , no.

3 , pp. 519-528, 2015.

[4] I. W. Mm, A. Azmi, C. Lee, and A. Mansor, "Kerf taper and delamination damage minimization of FRP hybrid composites under abrasive water-jet machining," Int. J. Adv. Manuf. Technol., vol. 94, no. $5-8$, pp. $1727-1744$, 2018 .

[5] Mustafa Armağan, "Cutting Performance of Glass-Vinyl Ester Composite by Abrasive Water Jet," J. Mater. Manuf. Process., vol. 32 no. 15 , pp. $1715-1722,2016$ 


\section{AWJM Performance Measurement of Sandwich Composites}

[6] A. Dhanawade and S. Kumar, "Experimental study of delamination and kerf geometry of carbon epoxy composite machined by abrasive water jet," J. Compos. Mater., vol. 51, no. 24, pp. 3373-3390, 2017.

[7] R. Selvam, L. Karunamoorthy, and N. Arunkumar, "Investigation on performance of abrasive water jet in machining hybrid composites," Mater. Manuf. Process., vol. 32, no. 6, pp. 700-706, 2017.

[8] Jagadish, S. Bhowmik, and A. Ray, "Prediction and optimization of process parameters of green composites

in AWJJ1 process using response surface methodology," Int. J Adv. Manuf Techno!., val. 87, no. 5-8, pp. 1359-

1370, 2016.

[9] M. A Azmir, A K. Ahsan, and A Rahmah, "Effect of abrasive water jet machining parameters on ararnid fibre reinforced plastics composite," Int. J Mater. Form., vaL 2, no. I, pp. 37-44, 2009

\section{AUTHORS PROFILE}

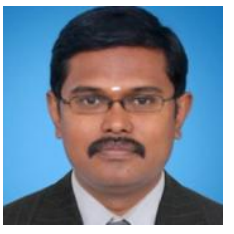

Dr. I. Siva is currently working as Professor in the Department of Mechanical Engineering, Kalasalingam Academy of Research and Education, Anand nagar, Krishnankoil-626126, India He has 15 years teaching as well as research experience. He is a reviewer more than 50 reputed journals $\mathrm{He}$ is a Member of Indian Society for Technical Education. His area of interests are polymer composite, materials characterization, tribology,FML

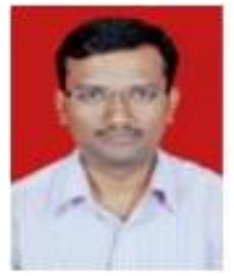

Avinash Shinde is currently working as Assistant Professor Department of Mechanical Engineering MKSSS's Cummins College of Engineering for Women Pune 411052, Maharashtra.His area of interests are polymer composite, materials characterization, tribology, DMA 